Research

\title{
Human-wildlife conflict interest: the psychometric reasons for the death of 28 hippos in the Gibe Sheleko National park (2019), Southwestern Ethiopia
}

\author{
Habtamu Wondimu ${ }^{1}$ (i) $\cdot$ Ashenafi Kebede ${ }^{1}$ \\ Received: 6 December 2021 / Accepted: 18 February 2022 \\ Published online: 28 February 2022 \\ (c) The Author(s) 2022 OPEN
}

\begin{abstract}
This study examines a hot issue that has received a lot of attention in 2019, Ethiopia, which is the death of over 28 hippos in Gibe-Sheleko National Park (GSNP) in southern Ethiopia, which has gone undiscovered until now. A psychometric explanation for the extinction of hippos was developed using a qualitative research approach that included in-depth interviews (28), focus groups (3), and key informant participants (3) who were carefully selected. Concerning the cause of the hippos' death we found three psychometric reasons: (1) the government-owned farm and the park's irresponsible management system are the primary causes of hippos' deaths, (2) crop, cattle, and property damage by the hippos, and (3) personal defense from the animals' attack. We found that the Ministry of Environment and Forests should support park administrative governments in upgrading habitat to boost food and water availability and prevent animal migration from park forests to habitations. Furthermore, we discovered that national and international media outlets performed their investigations into the interaction between the Gibe Woreda people and the animals following the deaths of over 28 hippos in the region. We understand that this had occurred for a political plot to get public attention and media publicity.
\end{abstract}

Keywords Human-wildlife rivalry · Psychometric reasons · Hippos · Government negligence · Crop-damage · Gibe River

\section{Introduction}

Human-animal conflict is not a new problem. It had been there for a long time. There are numerous causes for the conflicts. These conflicts arose as a result of the peoples' rapid population growth and land use transformation [11]. Furthermore, the struggle for shared natural resources and human food security exacerbates and influences tensions between humans and wildlife $[12,28]$. In rural areas, where livestock is completely dependent on agriculture and livestock, crops are often plundered and livestock is often killed by wildlife, resulting in economic loss [17]. Wild animals such as leopards, tigers (tigers), and elephants kill livestock, damage human property, spread illness, and even kill or hurt humans [6]. These events, especially those that result in loss of life, can result in retaliatory killings of wildlife, including those that are legally protected, endangered, or threatened. As a result, HWC impacts both human and wildlife life while endangering wildlife conservation goals [24].

The only way to ensure both wildlife management and human well-being at the same time is to take into account the numerous parts of conflict's social aspect. Such as the sociopolitical background, important stakeholders' notions, beliefs, prejudices, and attitudes, as well as an assessment of their interactions [4, 25, 34].

Habtamu Wondimu, habtamuw82@gmail.com | 'Sociology Department, Wolkite University, P.O. box. O7, Welkite, Ethiopia. 
Several articles like $[15,17,19]$ stated and investigated the relationships between humans and animals based on their conflict of interest in relating to the most endemic animals in sub-Saharan Africa, such as hippos. According to a report released by the International Union for Conservation of Nature and Natural Resources, the number of hippopotamuses in Ethiopia is decreasing due to a variety of factors such as environmental exploitation and habitat loss [8, 14]. The need for deeper information is critical because declines in Ethiopian hippos populations could have serious consequences for hippo conservation. However, in this study, we attempted to demonstrate or contribute by revealing the covert truth behind the death of 28 hippos in Gibe National Park (South-west Ethiopia) in 2019, as well as why they were killed and who is responsible. Furthermore, the study investigates hippos' behavioral changes as well as government officials' failures to respond to the issue.

Before three or four decades, the hippos in the Gibe Ethiopian National Park had good relationships with the people who rely on the Gibe River. People, particularly children, swim in the river without fear of hippos, and farmers have long used the river to irrigate their land and carry out various activities. However, the people's routine has changed, resulting in conflicts with the hippos. In 2019, the international news agency CNN and national media FANA broadcasters reported the deaths of 28 hippos from the Gibe River. According to the International Union for Conservation of Nature's red list of threatened species, the cause of their death is unknown (IUCN). Various governmental stakeholders attempted to investigate the cause of hippos death to promote national gain and in response to inflicting pain on the locals. But they didn't get any kind of clear interpretation, and society is still reluctant to reveal the truth about the animals' deaths (Hippos). Finally, the researchers who were appointed to investigate or perceive the issue that the animals were killed by society hunters related to trade and export of their canine teeth, and they conclude that the society has relations with illegal hunters. Their findings indicated a misunderstanding of society and a superficial investigation. As a result, there must be a deep understanding of the society to discover the truth about how and why the hippos were killed, as well as who killed them. However, this research attempted to contribute to the international media about the hidden facts behind the hippos death and its cause. And it examines government failures in protecting the lives of local peoples and animals in the study area, in addition to filling gaps in the previous literature.

\subsection{The objective of the study}

This study sought to examine the psychometric reasons behind the deaths of more than 28 hippos, the changes in the interaction between hippos and people. And the responsible stakeholder's failures to protect wildlife as well as the lives of the locals.

\subsection{Research questions}

Even though, several articles $[15,17,19]$ stated and investigated human-animal relationships based on their conflict of interest in relating to the most endemic animals in Sub-Saharan Africa, such as hippos. The following research questions were attempted to be answered and investigated in this study:

Research Question 1: How have interactions between hippos and people living near the Gibe River changed over time? Research Question 2: What are the reasons for the deaths of more than 28 hippos in Gibe Sheleko National Park?

Research Question 3: Why are responsible government stakeholders failing to protect wildlife as well as the lives of the locals?

\section{Methods}

\subsection{Description of the study area}

The Gibe Sheleko National Park (GSNP) is located in southwestern Ethiopia, $170 \mathrm{~km}$ from Addis Ababa, Ethiopia's capital city (see Fig. 1). The GSNP's astronomical coordinates are $05025^{\prime} \mathrm{N}$ to $06015^{\prime} \mathrm{N}$ and $35024^{\prime} \mathrm{E}$. When we look at its altitude, we can see that it is between 1050 and 1835 feet above sea level (see Fig. 1). Cheha, Abeshigie, and Enemor are the three Gurage zone districts that border the study area. Those people went about their daily lives, and the economic, social, and other aspects of their lives were based on agriculture using irrigation from the Gibe River. Since 2009/2010, GSNP has been designated as a regional park owing to its large endemics and species diversity conservation value, as well as its, 
Fig. 1 Study area location map. Source: GPS survey data, 2016

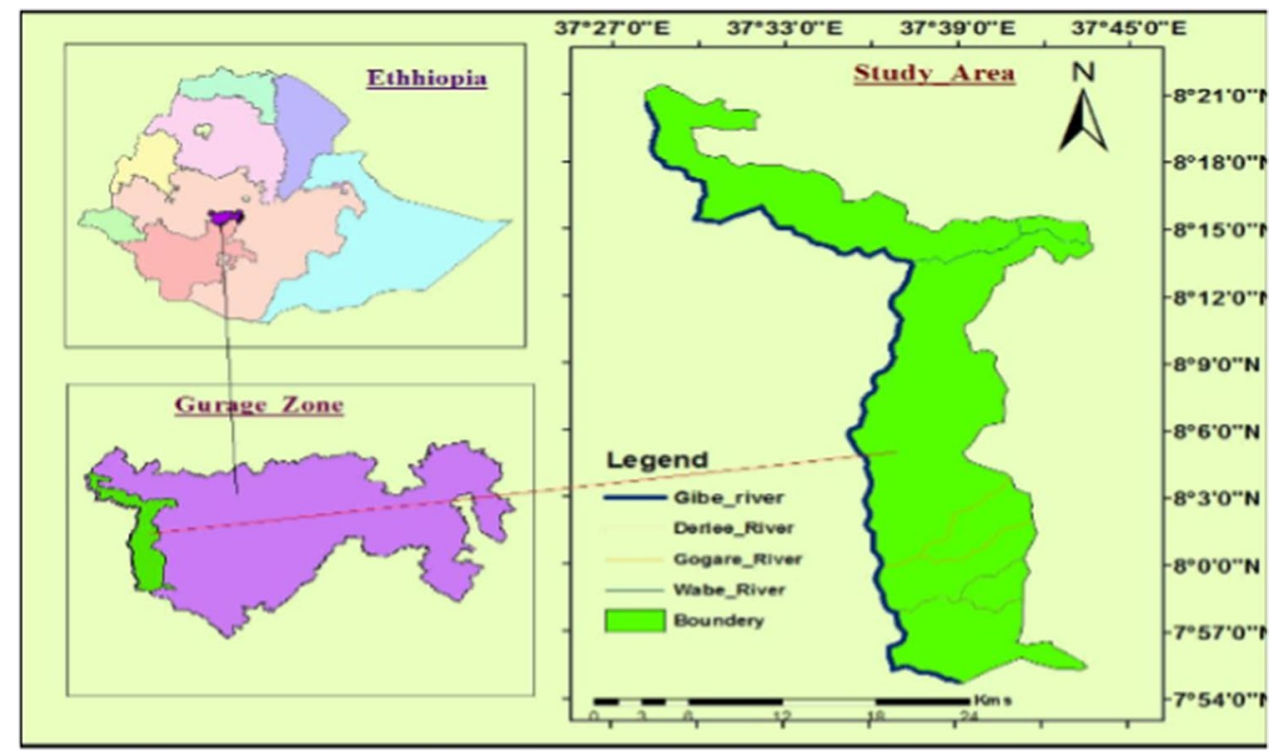

being home to numerous migratory and endemic bird species $[2,3]$. It covers $360 \mathrm{~km}^{2}$ and is distinguished by a diverse landscape, flora, fauna, and habitat types, as well as deep gorges formed by the Gilgel Gibe and Wabe rivers. 17 mammal species, including greater kudu and a few hippos in the river valley, make up the distinct but somewhat obscure wildlife. Over 200 species of birds have been recorded, including red-winged Pytilia and white-winged cliff chat.

\subsection{Study design}

This study used a qualitative approach; however, the researchers used a phenomenological research design [34]. The phenomenological study design according to Groenewald [13] shows or investigates the conscious and lived experience of some specific individuals through examining time, space, and personal history to understand social reality. With this in mind, this study employed a phenomenological study design to assess the depth of understanding of why and how the hippos were killed, relating to the locals' lived experiences as well as the silence of responsible stakeholders in responding within a set time frame [18]. Data for the study were collected from carefully selected participants in the study areas between June and July 2019. In terms of the research approach, this study used a qualitative method to assess the lived experiences of people who live on and rely on the Gibe River [29, 33]. We investigated the society's lived to experience concerning the interaction they had with the hippos, as well as the progressive behavioral changes they observed on the hippos and the factors that led to those behavioral changes. In addition, the efforts of the media and government stakeholders to promote national gains by inflicting or inducing pain on locals were investigated.

\subsection{Participants}

The Gibe National Park is one of Ethiopia's national parks. This national park is located on the northern side of the southern region, in the upper part of the OMO Gibe basin, and is bordered on the southern and western sides by the Oromiya regional state. The Gibe National Park is found in the southwest of Ethiopia $174 \mathrm{~km}$ away from Addis Ababa, the capital city of Ethiopia [2]. The park is home to a diverse range of wildlife species. So far, 17 larger mammals and over 200 bird species have been recorded in the park's various habitats. The Lion, Greater Kudu, and Hippopotamus are among them [2]. The most common are the Bohor, bushbuck, leopard, waterbuck, wild cat, serval cat, bush pig, warthog, common baboon, and monkey (ibid). We used a qualitative study design in this study. As a result, our participants were chosen using purposive (judgmental) sampling methods. The Gibe Sheleko National Park (GSNP) is bounded in the three districts of Gurage Zone such as the Cheaha, Abeshigie, and Enamor. This study primarily relied on the Gibe kebeles included in the Abeshege district, which is the one district bound the Gibe Sheleko National park. Because the hippos were found dead in the Gibe Woreda (Kebeles), such as Jama-Sefer Kebele, Kebtberet Kebele, Shewaber Kebele, and Deldiye Kebele. The Purposive sampling method was used to recruit sample kebeles from the four selected Kebeles of Abeshgie District based on park officials' recommendations based on their level of interaction 
Fig. 2 Artifact of the dead hippo, a photo taken while we are in the field

Fig. 3 The hippos found dead in the Gibe river were retrieved from aricanews.com
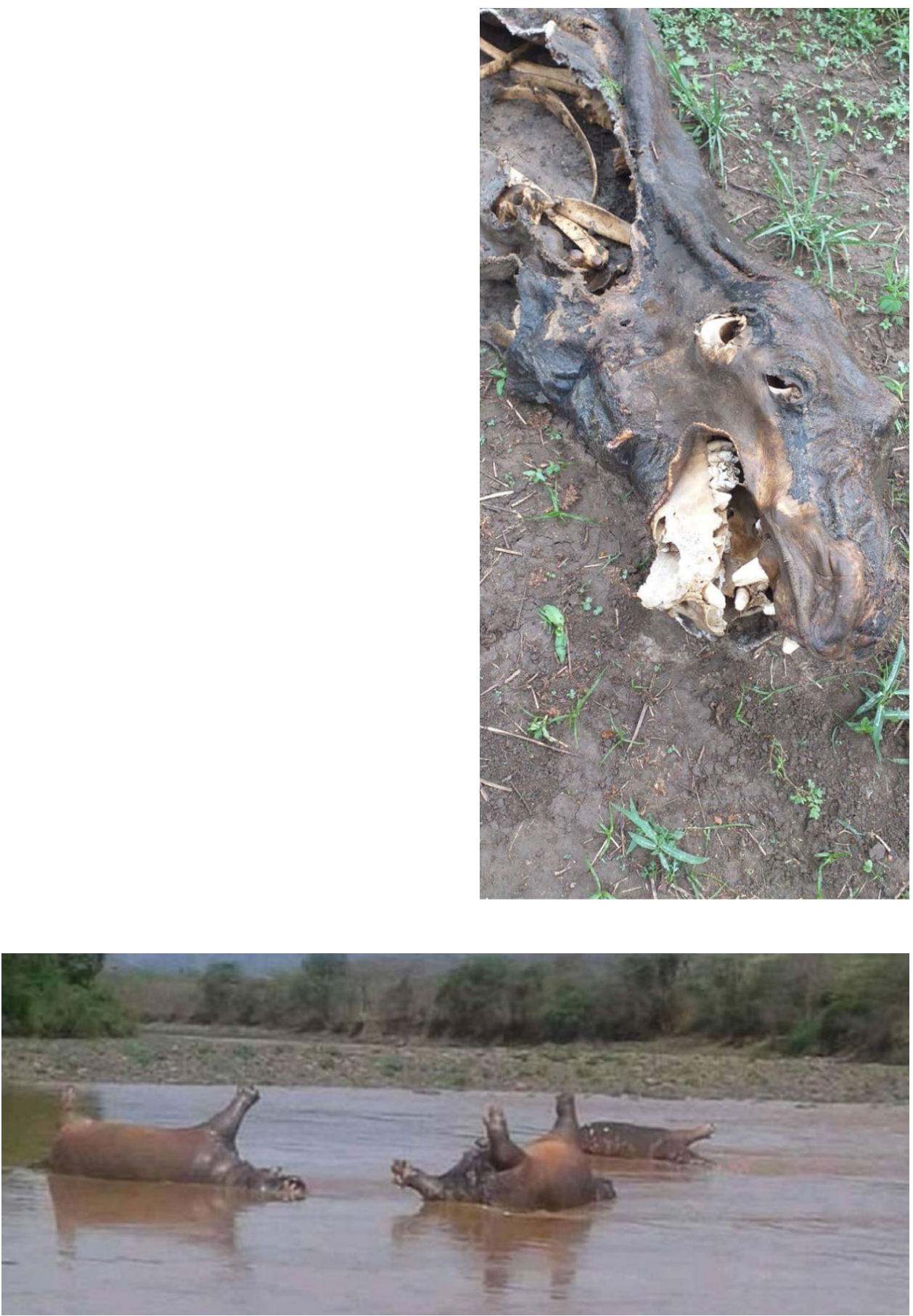

with and reliance on the national park. This study includes the participants who spent two and more than two decades (who spent at least 20-40 years and above in the areas) in the areas, and we used it as an inclusion criterion. We used this inclusion criterion in the hopes of gathering useful information about their smooth interactions and how they changed their interactions over time, as well as examining their daily life experiences related to the issue we under-investigated. Figures 2, 3, and 4 exhibit the artifacts of deceased hippos found in the Gibe River as well as near the residents' dwellings and in the finding of their meals outside the park. 
Fig. 4 A group of hippos in searching for their daily meal

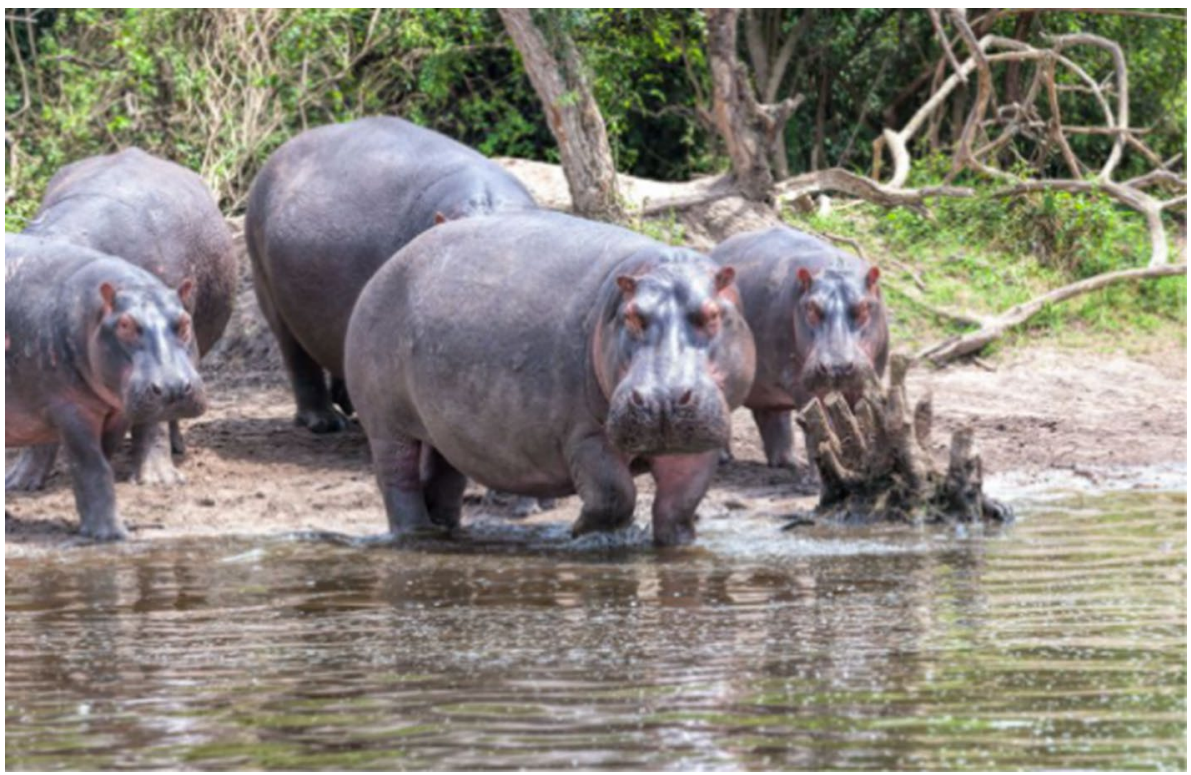

\subsection{Data collection instruments and procedure}

This study was reviewed and approved by the Wolkite University research center. Before collecting data for the stated objectives, we provided a formal letter of request to study participants written by the Wolkite University sociology department and research institute. Following that, eligible participants were identified based on the study inclusion criteria. Participants were asked if they would be willing to participate and provide information about the issue in the study. To ensure the research's validity and reliability, we provide a brief explanation to participants about the study's overall purpose. The issue of confidentiality is maintained by informing participants that they may decline to participate if they are unwilling to reveal the intended information. We also gave them each an informed consent form, read it aloud to the informants, and answered their questions about their agreement and other issues of confidentiality. Participants agreed to participate in the study after hearing and reading about informed consent. The data collection process was held in June-July, 2019. To achieve data saturation, an in-depth interview, focus-group discussions, and key-informant interviews were used as data collection methods. The in-depth interviews were conducted with people chosen purposively from the Abeshgie district and its four Kebeles (Jama-Sefer Kebele, Kebtberet Kebele, Shewaber Kebele, and Deldiye Kebele). An in-depth interview was conducted to investigate the hippos' progressive behavioral changes and the type of interaction the residents had with wildlife-based on their lived experience, as well as the cause of the deaths of over 28 hippos, why they occurred, and their grievances regarding the government's response to the issue. For this purpose, we contacted 28 participants from the four kebeles, and we select seven people from every four Kebeles. The interview questions were open-ended, not double-barrelled (one question touches only one topic), but short [7]. Interview questions were created by the authors and recorded using an interview guide for participants. This guide tailors the purpose and content of the interview to the participant of the study. Researchers collect data from participants via tape recorders and note writing. In these sessions, participants were free to express their thoughts and modify their opinions as needed. Table 1 presents the profile of the four selected kebeles found in the Abshgie District, including their age and sex. The interview questions were also given to each participant in the form of a one-on-one interview for $25 \mathrm{~min}$. This study also used FGD based on the inclusion criteria (Focus group discussions). We held three focus group discussions, each with eight participants. The focus group discussion was held to deeply understand the Gibe Woreda (Abshgie) district Kebeles residents' reflections on what the Gibe Sheleko National Park (GSNP) meant to them, as well as the wider media misconceptions about the death of the 28 hippos and government failures to conserve wildlife, particularly hippos. Note that, Participants in the interview were also employed in the FGD session. Finally, a key informant interview with three participants was conducted. The participants included Park officials as well as some community elders who are well-versed and knowledgeable about the issue. Interview guides that elicit responses on various aspects related to the specific objectives of the study under investigation are prepared for this purpose. 
Table 1 Profile of the participants of four selected Kebles (Abeshgie District). Source: Own survey, 2019

\begin{tabular}{|c|c|c|c|c|c|}
\hline Code & Sex & Age & Occupation & Place of interview & Date of interview \\
\hline \multicolumn{6}{|c|}{ Profile of Jamma-Seferkebele participants } \\
\hline 1-Ind-1 & M & 65 & Farmer & JammaSefer & June 23, 2019 \\
\hline $1-$ Ind-2 & M & 53 & Scout & JammaSefer & June 23, 2019 \\
\hline $1-\operatorname{lnd}-3$ & $\mathrm{~F}$ & 38 & Daily laborer & JammaSefer & June 23, 2019 \\
\hline $1-$ Ind-4 & $\mathrm{F}$ & 42 & Widow farmer & JammaSefer & June 25, 2019 \\
\hline $1-$ Ind-5 & $\mathrm{F}$ & 45 & Farmer (now injured by hippo) & JammaSefer & June 25, 2019 \\
\hline 1-Ind-6 & M & 60 & Farmer & JammaSefer & June 25, 2019 \\
\hline 1-Ind-7 & M & 46 & Gov't office & JammaSefer & June 25, 2019 \\
\hline \multicolumn{6}{|c|}{ Profile of ShewaberKebele participants } \\
\hline $2-\operatorname{lnd}-1$ & M & 45 & Daily labor & Shewaber kebele & June 28, 2019 \\
\hline $2-\operatorname{lnd}-2$ & $\mathrm{~F}$ & 39 & Daily labor & Shewaber kebele & June 28, 2019 \\
\hline $2-$ Ind-3 & $\mathrm{F}$ & 27 & Daily laborer & Shewaber kebele & June 28, 2019 \\
\hline $2-$ Ind-4 & M & 32 & Scout & Shewaber kebele & June 28, 2019 \\
\hline $2-$ Ind-5 & M & 29 & Farmer & Shewaber kebele & July 2, 2019 \\
\hline $2-\operatorname{lnd}-6$ & M & 75 & Elder & Shewaber kebele & July 2, 2019 \\
\hline 2-Ind-7 & $\mathrm{F}$ & 40 & Farmer & Shewaber kebele & July 2, 2019 \\
\hline \multicolumn{6}{|c|}{ Profile of KebetberetKebele participants } \\
\hline $3-$ Ind-1 & M & 73 & Elder & Kebetberetkebele & July 8, 2019 \\
\hline $3-$ Ind-2 & $\mathrm{F}$ & 29 & Local market merchant & Kebetberetkebele & July 8, 2019 \\
\hline $3-$ Ind-3 & $\mathrm{F}$ & 37 & Daily laborer & Kebetberetkebele & July 8, 2019 \\
\hline $3-\operatorname{lnd}-4$ & M & 42 & Scout & Kebetberetkebele & July 8, 2019 \\
\hline $3-$ Ind-5 & M & 39 & Farmer & Kebetberetkebele & July 13, 2019 \\
\hline $3-$ Ind-6 & M & 75 & Farmer & Kebetberetkebele & July 13, 2019 \\
\hline 3-Ind-7 & $\mathrm{F}$ & 40 & An official in gov't farm & Kebetberetkebele & July 13, 2019 \\
\hline \multicolumn{6}{|c|}{ Profile of DeldiyeKebele participants } \\
\hline 4-Ind-1 & M & 40 & Fisher & Dildiyekebele & July 20, 2019 \\
\hline $4-I n d-2$ & M & 39 & Fisher & Dildiyekebele & July 20, 2019 \\
\hline $4-I n d-3$ & $\mathrm{~F}$ & 34 & Daily laborer & Dildiyekebele & July 20, 2019 \\
\hline $4-I n d-4$ & M & 51 & Farmer & Dildiyekebele & July 20, 2019 \\
\hline $4-I n d-5$ & $\mathrm{~F}$ & 42 & Farmer & Dildiyekebele & July 4, 2019 \\
\hline 4-Ind-6 & $\mathrm{M}$ & 79 & Elder & Dildiyekebele & July 4, 2019 \\
\hline
\end{tabular}

\subsection{Data analysis}

The qualitative data collection instruments used in this study, such as in-depth interviews, focus group discussions, and key informant interviews, assist the researchers in developing an inductive thematic analytical strategy [22]. Data from in-depth and key informant interviews, as well as focus groups, were analyzed thematically or qualitatively. In other words, data on the following topics were analyzed:

- The interactions between hippos and the people who live near the Gibe River (residents).

- The reason for the deaths of 28 hippos in Gibe Sheleko National Park.

- The role of government officials in protecting wildlife and residents' lives. This theme was investigated by emphasizing national gains while inflicting pain on the locals.

As a result, data from study participants were collected using a tape recorder and taking notes, respectively. However, the data was reviewed by reading and listening to the recorded data on a tape recorder, which was used as a data collection instrument. 


\section{Results}

\subsection{How have interactions between hippos and people living near the Gibe River changed over time?}

Gibe National Park was officially established in 2001 E.C., but the people who inhabited the area began to live there five to six decades ago, living as farmers and daily laborers on the government-owned farm. During this time, people coexist peacefully with animals, particularly hippos, which are found in Gibe National Park. During the interview, one of our key informants from Jamma Sefer kebele said how the interplay among locals and animals looks as if inside the early period, while people were swimming in the Gibe River and fetching drink water from the river, they would play with hippos by chasing them. However, after 2019, the hippo's behavior completely changed, becoming very aggressive, and the relationship between humans and hippos changed year after year, becoming very serious today. The reason for the changes in this human-animal relationship is the transformation of land use by the government-owned farm. According to Elder from Shewaber Keble, regarding changes in hippo behavior said, the reason is as follows:

"In pastime, the government-owned farm cultivates fruit especially orange parallel to Gibe river through irrigation, accordingly the hippo easily gets its food (grass) from this fruit farm without going far to the peoples' village and their farm area as well, however without considering the life of hippo and discussing the issue with concerned tourism office about the futurity of the hippo, the government transforms the land use from fruit farm to maize seed farm by demolishing the orange plant and established a trench in order not enter hippo to the farm. Now the hippo forced to go to human's village and farm in search of food here is the conflict began between human and the hippo." (2-Ind-6)

In the same vein, another In-depth interview participant concerning animal attacks revealed that large mammals (Hippopotamus) are to blame for deadly attacks on humans; these animals primarily harm residents, and many people have died since 2015. The majority of the deaths have occurred when locals were protecting their crops from raiding animals (hippos), when humans came into contact with the animals by accident, particularly on paths near water at night, or when humans came into contact with injured animals whose normal sense of caution was impaired. As a result of the hippo's search for food in the village and on individual farms, the villagers began to struggle with the hippo to protect their farm and secure their food. In addition, in the year 2019, the hippo began to react, killing four people and injuring more than ten. As the informants opined, while all of this was going on, government officials such as the farm director, security, and scouts did nothing to protect the people who were victims of the hippo's aggressive behavior. As evidenced by the fact that the government, despite gaining national attention for the hippos' killing, was unable to see the locals' anguish while battling the animals for their daily food. Similarly, the FGD \#1 response on wild and wildlife revealed that residents had a positive attitude toward wildlife, particularly hippos. The reason they gave in the discussion was the importance of hippos as a tourist attraction, and they believe the location could be a future tourist destination, which is very beneficial to future generations.

The major reason for the threat of their relationships with the hippos was the government responsible bodies using the Gibe River to cultivate various crops such as maize and encircling the areas with the trench. However, these trenches prevent the hippos from entering and obtaining their food from the farm, as revealed by the selected participants, leaving the hippos with no choice but to turn their faces in the residents' farm and damage their agricultural foods, resulting in aggressive relationships between the hippos and the locals. $[3,20,27]$ in the same vein assert that HWC, which is caused by human-wildlife competition for shared natural resources, has an impact on human food security and the well-being of both humans and animals. This study result similarly revealed that the hippos smooth relationships with the people turned aggressively due to the locals' interest to protect their food security and to promote their wellbeing.

\subsection{What are the reasons for the deaths of more than $\mathbf{2 8}$ hippos in Gibe Sheleko National Park?}

The sudden mass death of hippos in Gibe River became breaking news of national and international TV including CNN and FANA broadcasting in the year 2019/2020, and now all concerned bodies, including Wolkite University team members, began to rush here and there to investigate the cause of this mass death of hippos. However, they do not receive any tangible or clear information about the cause; instead, they simply speculate that it may be related to environmental change. 
According to our informants from four Kebeles in the study areas, the how and why questions for the death of hippo in 2019 are related to human factors, specifically locals and the government-owned farm, rather than natural factors such as environmental changes, as suggested by stakeholders in various media. Informants present the reason for the mass hippo death in Gibe River in two ways, one as a fundamental factor and the other as an immediate cause. As we discussed in the previous section about the relationship between humans and hippos, the governmentowned farm and the park's irresponsible management system are the primary causes of hippos' deaths. Similarly, the findings of $[19,31]$ identified some challenges affecting the conservation and management of national parks in Ethiopia including a lack of sense of ownership, limited awareness, population growth, a lack of coordination, conflicts over resources, boundary issues/lack of boundary, invasive species, illegal charcoal production, climate change, and poverty, which leads to maltreatment of animals residing in the parks. In the same vein, the Gibe Woredas residents (Locals) who have lived in the study area for twenty to forty years on average have complained about the park concerning their farmland, firewood, grazing land for their cattle, and so on. According to in-depth interview participants, (1-ind 1 and 3-1nd6), complaints about what does the park means to them are as follows:

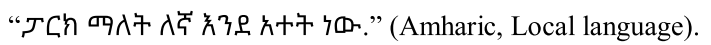

The elder (the key-informant informant from Kebtberet Kebele) presents his viewpoint in Amharic (local language) by comparing the park to diarrhea. He says that a person infected with diarrhea does not go far because he needs a toilet nearby and the pain is very high; similarly, the park does not allow us to go far like feeding our cattle, collecting woods, and collecting grass for our house cover, so we are in pain, and who knows in the long run. This demonstrates that, despite its foreign currency and environmental conservation, the Gibe Sheleko National Park forces residents to abandon their daily routine because security prevents them and their animals from accessing grass and their daily meals from the park and river. It is unjust for the government to prioritize the souls of these endemic animals over the souls of its citizens. As a researcher, we can understand the locals' fear of the park because, in the first place, when the park was established, they did not consent and their viewpoint is not represented. Their concern stems from the fact that there is no clear demarcation between the park and their farmland, and they fear that they will be displaced from their longestablished location. This is returned to them, forcing them to regard the friendly hippo and other animals as enemies. They began to deforest communal natural resources and destroy animal food like grass with fire. Similar to our study findings, research conducted by $[26,32]$ revealed that farming and plowing are the primary sole tasks for farmers to feed their families, and for farming, there must be a place to plow and deforestation, as well as some animals that eat the farmers'farming products, including larger mammalians. This study, on the other hand, demonstrated that locals, to prevent hippos from crushing their farming products, deforest the area, and burn it down.

On the other hand, a farmer (2-Ind-5) who studied until 8th grade concerning the park opportunities and challenges states that, as you know that this place is arid, it's very hot and cannot get rain even in the summer properly but after the establishment of the park and forests are protected we get rain in regular and plow our land and get a good product, the park brings hope for us however at the same time it brings wild animals and wild fly which attacked our cattle and cause disease for cattle's, the hippo destroyed our farm as well. This young man farmer concludes his statement as follows:

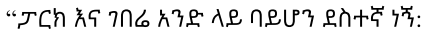

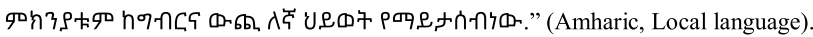

Meaning unless there is a clear demarcation exists between the farmland and the park, establishing a buffer zone life is difficult for the farmer and the hippo because for us there is no life without the farm.

During the second focused group discussion (FGD), most informants point to their presence on the governmentowned farm as a responsible and fundamental cause of the hippo's death as follows. During the discussion, they named several hippos concentration centers, including GumareBahir, Moter or Gumare (hippos) camp, and Ashewa, all of which are located in a nearby government-owned orange farm. Most hippos live in this area and get their food from the fruit farm without having to travel far. However, without considering the future fate of hippos and discussing the issue with concerned officials such as the Gurage zone tourism office, the land use is transformed, from orange farm to maize seed farm, and makes faience to protect their farm from hippo without leaving a buffer zone for animals, this time hippos life becomes trouble and forced to travel a long distance to the locals' village and their farm in search of food. Various points 
of view are expressed during FGD, interviews, and informal conversation sessions regarding the immediate cause of the hippo's death. The cause, in this case, is related to the local farmers. Some informants who lost their families and were injured by hippos state the following:

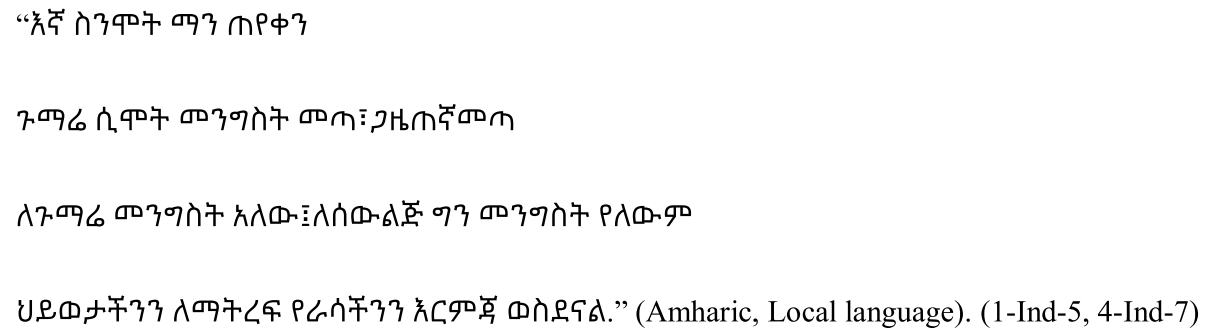

Meaning, there was a government for hippos because it is believed to bring currency for national gain, but we humans are not protected when hippos kill four people, injuring more than ten, and destroy our farm. So, according to these informants, hippos take a precautionary measure to protect their lives by claiming that we do not see simply until we all die. However, it is not stated how they measure hippos. However, in our informal discussions, some informants revealed that the measure is implemented in such a way that hippo is poisoned by feeding maize products on the farm. As a researcher, we ask questions related to this issue for the FGD participants to cross-check the information, but some of them are afraid to respond to the issue, while others say, "We hear the issue, but it is the responsibility of the government to take a sample and investigate the reason". Unfortunately, the stakeholders are unable to collect the sample and must instead make their assumptions about the cause through various media by relating it to natural factors. Data from study participants revealed that the government's media coverage of the deaths of over 28 hippos was intended to increase public demand to strengthen the government's relationships with foreign outlanders. These study findings are related to the $[15,16,30]$ political conspiracy theory methods for political propaganda. The federal government used the mass hippos deaths in the Gibe Sheleko National Park (GSNP) for political agendas and to draw public and government attention without feeling the pain of the locals and overweight the animals over the people who live in the Gibe Woredas and some selected Kebeles in the study.

\subsection{Why are responsible government stakeholders failing to protect wildlife as well as the lives of the locals?}

Stakeholders are individuals or groups who are either negatively or positively affected by a proposed intervention, or who can influence the outcome [23]. Stakeholders inquired about the park to acknowledge that numerous NonGovernmental Organizations and Community Based Organizations in the area benefit from donations of old equipment, uniforms, furniture, and other goods from the park that is no longer in use. Although cash donations were requested, the emphasis was on donations of goods. Small business donations were also requested [1]. In this section, we assess the failures of the GSNP managerial office (staff) to conserve wildlife and the director of agricultural and natural resource management offices of Gurage Zone failures to promote the well-being of residents before media coverage of the issue reaches a wider audience.

\subsubsection{The responsible stakeholders' negligence}

In terms of the role of stakeholders, the tourism office failed to protect the lives of locals and the hippo. They failed to draw a line and leave a buffer zone between the farmland to the park; they also failed to discuss the changing relationship between humans and animals, particularly hippos, and to take precautionary measures before the loss of human life and hippos; and they failed to discuss the impact of the government-owned farm on hippos'lives. Note that, the responsible stakeholders we used in this study are those GSNP managerial offices, volunteer scouts, agricultural and natural resource management offices of Gurage Zone. One of our informants (4-Ind-5) concerning responsible stakeholders failures in the park claims that "the stakeholder's failures begin when they intermediate us (the locals) by comparing our lives to animals", and to back up his claim, he says: 


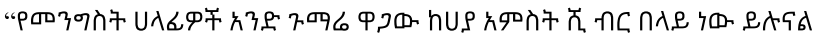

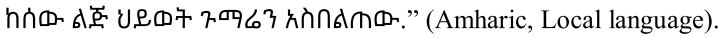

Meaning, when we discuss the issue with officials, they say one hippo costs more than 25,000 birrs, and they place more value on hippo than human life; this attitude of stakeholders over locals may also be responsible for the improvement of the smooth relationship between humans and hippo. The informant claims his grievances about how the people's souls could be compared to animals and, he said little attention towards the communities shows the government's negligence to the lives of the residents. The FGD participants $3 \#$ concerning the park negligence confirmed that:

"Of course, we recognize that animals are truly wild and that they may attack a person's private property at any time. However, there may be some rules or laws that penalize or prohibit animals. Every farmer's life is jeopardized unless the laws are followed in our village." (3-Ind-6)

In the same vein, one of the in-depth interview participants stated "We saw no one (park personnel) before the hippos died, and after the hippos died, several governmental authorities tried to conduct interviews with our village residents, but this should have been done before these things happened, they spoke with us for political reasons and inquiries from various international media, this could not prevent the residents and wildlife conflict, the government, on the other hand, strong measures and should promote the locals' wellbeing by protecting the farming product from these endemic animals, particularly from the remaining hippos." The study findings concerning property protections by-laws revealed that attacks by wild animals not held in captivity are not normally controlled by the common law rule of wild-natured animals. This concept does not protect property owners from liability for animal attacks that occur on their land, also it does not protect them from liability if they were negligent in preventing the harm.

\subsubsection{Residents' incapacity to participate in local agendas}

Public meetings incorporate multiple groups of stakeholders for a specific goal. Public meetings are conducted to involve a diverse audience in the sharing and discussion of information. However, in the study areas, the governmental accountable stakeholders in the GSNP made a variety of decisions without consulting the community. One of our in-depth interview participants concerning the locals' incapacity to participate in the developmental agendas revealed that,

"...we all farmers in the Gibe Woreda use Gibe River as the main source of irrigation for our farming goods. However, there is a government-owned farm in the village where we worked for a while, but after the government changed the land use from fruit farm to maize seed farm by demolishing the orange plant, we began to farm our land, and the government encircled its farmland with trenches, but no one held a public meeting to educate the community about our perception and need. They take their measurements without taking us into account; this reflects the government's inability to prioritize the lives of impoverished farmers." (1-Ind-3)

Chandrasekhar [9] stated, community engagement is critical for emergency sanitation, and the society or community must get adapted to their surroundings' goals since every government program must be compatible with societal cultural norms and religious myths. Despite the Chandrasekhar [9] findings, research participants contended that "The majority of Gibe Woreda's population have been relocated from the northern parts of Ethiopia. Furthermore, the GSNP was established in 2001, and the government before the creation did not do a need assessment, nor did they activate their strategy to promote community awareness. We, as a society, do not take part in the official and informal tracings of the community's organizational framework. The participant also stated that while many of the community inhabitants here have a positive attitude toward the Park and the animals, they do not know how to support themselves with the park's organizational structure; therefore, the park should give routine vocational training skills."The findings result from the participants showed that the government stakeholders in the regions do not take a participatory approach, in which citizens do not have the right to participate in the Park or government program and do not have a voice or the ability to express their rights. This, on the other side, disrupts the country's development process. 


\section{Discussion and conclusion}

This research looks at the major issue that has gotten a lot of attention in 2019, Ethiopia, which is the death of over 28 hippos in GSNP in southern Ethiopia, which has gone unnoticed until now. However, this study presents a psychometric rationale for the demise of hippos through a qualitative study that includes in-depth interviews, focus groups, and key informant participants who were chosen on purpose. In this study, three issues are investigated: (1) the reasons for death over 28 hippos in the GSNP, (2) the interaction changes between hippos and people living near the gibe river, for which we investigated four Gibe Woreda kebeles, and (3) the failure of responsible governmental stakeholders to handle the issue, which we saw in this case by relating to governmental negligence and residents' inability to participate in public agendas. Concerning the alterations in interaction between hippos and people living near the Gibe River, the findings of this study indicated two factors that endanger the hippos' smooth connection with the people living near the Gibe kebeles (Jama-Sefer Kebele, Kebtberet Kebele, Shewaber Kebele, and Deldiye Kebele). These are the following reasons: (1) the transformation of land usage by government-owned land, and (2) human-wildlife competition for shared natural resources. According to the findings, entrenching of the governmentowned property causes the hippos to be unable to escape the agricultural goods grown by the government, causing the hippos to shift their direction to harm the crop products of the local population [21]. This, in turn, leads to an aggressive relationship between humans and animals (hippos). Second, the community's shared natural resource is another cause for the difficulty and uneven connections between the animals (hippos) and people [10, 31]. The hippos, as a result of the change of government-owned property, go and harm the local agricultural production, and to enhance food security and well-being, the inhabitants have forcefully taken their measurements to turn their smooth connections. In the same vein $[3,20]$ assert that HWC, which is caused by human-wildlife competition for shared natural resources, has an impact on human food security and the well-being of both humans and animals. Despite previous research, the outcomes of this study revealed that the smooth connections between hippos and humans were jeopardized owing to the alteration of land utilization by government-owned land around the GSNP. This was a significant contributor to the aggressive relationships that were not identified in the other research findings.

Concerning the second research question, which is the reason for the hippos' deaths in the study areas, this research has confirmed that the hippos were killed by local inhabitants. Several public universities in Ethiopia (Wolkite University and other public research institutes for foreign and national broadcasting TV organizations such as CNN and FANA) attempted to explore the problem but were unable to get accurate information concerning the reason for the hippos' catastrophic extinction. They were unable to obtain solid information because they used the issue to seek public and government attention without feeling the anguish of the residents and prioritized the animals over the people who live in the Gibe Woredas and media coverage. Despite their discoveries, we discovered three reasons for their deaths in this study: (1) the government-owned farm and the park's reckless management system are the primary causes of hippos' deaths, (2) crop, cattle, and property damage by the hippos, and (3) personal defense from the animals' attack. More deaths will occur in the regions unless park managers can offer appropriate animal management. Similarly, Aryal et al. [6] and Aryal [5], in rural areas where livestock is completely dependent on agriculture and ranch, crops are often plundered and livestock is often killed by wildlife, resulting in economic loss. Wild animals such as leopards, tigers, and elephants kill livestock, damage human property, spread disease, and even kill or hurt people. The incident urges the community to kill wildlife and protect natural resources and property. Based on the findings of this study, we recommend that the park's management, including the administrative and volunteer scouts, secure animal food security and support sustainable growth in the park, as well as a strong conservation effort. We hope that this will be beneficial to both the animals and the communities that live in the regions.

Concerning the third research question, which is about the failure of responsible stakeholders to enhance wildlife and the lives of locals, we look at two issues: (1) the negligence of responsible stakeholders, and (2) residents' inability to engage in local agendas. It should be noted that the responsible stakeholders we employed in this study are the Gurage Zone's GSNP administrative offices, volunteer scouts, agricultural and natural resource management offices. We noticed that park administrators prioritize the animals' souls and livelihoods over the population of the study region (Gibe Woreda), demonstrating their indifference to the villagers' anguish. Furthermore, we discovered that national and international media outlets performed their investigations into the interaction between the Gibe Woreda people and the animals following the deaths of over 28 hippos in the region. We saw that this had occurred for a political plot to get public attention and media publicity. According to Chandrasekhar [9] and Solomon et al. [32], community involvement is important for emergency hygiene, and because government programs must adapt 
to social norms and religious myths, societies or communities need to adapt to their environmental goals. Despite the Chandrasekhar [9] assumptions, we discovered that the government stakeholders in the regions do not take a participatory approach, which means that locals do not have the right to engage in the Park or government programs, and they lack a voice or the capacity to express their rights. On the other hand, this undermines the country's development process.

\subsection{Study limitation, and recommendations}

According to Proclamation No. 541/2007, on Development Conservation and Utilization of Wildlife, the Ministry of Wild and Forest (Ethiopia) undertakes the required investigation on wildlife posing a threat to human life and property, and takes appropriate measures to minimize and prevent the threat, reporting to the Ministry when the case is really beyond their capacity. However, no one looks into the property, crop, and human injuries and damage caused by the animals in the study regions. This violates the FDRE proclamation on human-animal relationships and suggests that the responsible park officer came into the research areas to interview after the hippos died for political conspiracies and media publicity, which we found disappointing. Here we recommend, the Ministry of Environment and forests must help park administrative governments in improving habitat to increase food and water supply and to reduce animal migration from the park forests to habitations. And it is vital to make the local people aware of what they should do and what they should not do to reduce disputes. Trainers should come from the Forest Wildlife Officials, as well as neighborhood scouts and security, to provide vocational training and awareness creation scheme. The entire amount of agricultural damage and the number of livestock deprecated were not measured, which was one of the study's limitations. Furthermore, a suitable evaluation of wild animal resources in the forest region should be undertaken to determine the forest's carrying capacity to support wild animals. And, if it is considered a limitation, we found and could only acquire three images of the deceased hippos for data clearing. Furthermore, the majority of the data was gathered by deeply engaging in the study regions and offering some money to the participants; nevertheless, further research should be conducted by observing the issue while completely participating.

Acknowledgements The authors want to thank all the respondents in the study areas who gave more valuable pieces of information without cupidity.

Authors' contributions Both HW and AK involved in the study conception and design and drafting manuscript preparation equally. Both authors reviewed the results. Both authors read and approved the final manuscript.

Funding The authors have not received any financial grants from other governmental and non-governmental organizations to do this research.

Data availability The datasets generated during and/or analyzed during the current study are available from the corresponding author on reasonable request.

\section{Declarations}

Ethics approval and consent to participate Ethical approval was waived by the local Ethics Committee of Wolkite University, Ethiopia given the retrospective nature of the study and all the procedures being performed were part of the routine care.

Consent for publication Eligible participants were identified based on the study inclusion criteria, and participants were asked if they would be willing to participate and provide information about the issue in the study. To ensure the research's validity and reliability, we provide a brief explanation to participants about the study's overall purpose and the issue of confidentiality maintained by informing participants that they may decline to participate if they are unwilling to reveal the intended information. We also gave them each an informed consent form, read it aloud to the informants, and answered their questions about their agreement and other issues of confidentiality. Participants agreed to participate in the study after hearing and reading about informed consent.

Competing interests The authors have no conflicts of interest to declare that are relevant to the content of this article.

Open Access This article is licensed under a Creative Commons Attribution 4.0 International License, which permits use, sharing, adaptation, distribution and reproduction in any medium or format, as long as you give appropriate credit to the original author(s) and the source, provide a link to the Creative Commons licence, and indicate if changes were made. The images or other third party material in this article are included in the article's Creative Commons licence, unless indicated otherwise in a credit line to the material. If material is not included in the article's Creative Commons licence and your intended use is not permitted by statutory regulation or exceeds the permitted use, you will need to obtain permission directly from the copyright holder. To view a copy of this licence, visit http://creativecommons.org/licenses/by/4.0/. 


\section{References}

1. Abebe FB, Bekele SE. Challenges to national park conservation and management in Ethiopia. J Agric Sci. 2018;10:52.

2. Abie K, Tilahun B, Feyisa A, Kumssa T, Amare A. Diversity and habitat association of medium and large mammals in Gibe Sheleko National Park, Southern Ethiopia. Ecol Evol. 2021;11:12251-8.

3. Amare A. Conservation challenges of Gibe Sheleko National Park, Southwestern Ethiopia. Nat Res. 2015;06:286-9.

4. Amare Y, Serekebirhan T. Human-wildlife conflict around Midre-Kebid Abo Monastry, Gurage Zone, Southwest Ethiopia. Int J Biodivers Conserv. 2019;11:212-29.

5. Aryal A. Conservation conflict: factor people into tiger conservation: conservation conflict. Nature. 2015;522(7556):287. https://doi.org/ 10.1038/522287a.

6. Aryal A, Brunton D, Ji W, Barraclough RK, Raubenheimer D. Human-carnivore conflict: ecological and economical sustainability of predation on livestock by snow leopard and other carnivores in the Himalaya. Sustain Sci. 2014;9(3):321-9. https://doi.org/10.1007/ s11625-014-0246-8.

7. Bryman A. Social research methods. 5th ed. Oxford: Oxford University Press; 2016.

8. Buruso FH. Habitat suitability analysis for hippopotamus (H. amphibious) using GIS and remote sensing in Lake Tana and its environs, Ethiopia. Environ Syst Res. 2017. https://doi.org/10.1186/s40068-017-0083-8.

9. Chandrasekhar D. Digging deeper: participation and non-participation in post-disaster community recovery. Community Dev. 2012;43:614-29.

10. Demeke D, Afework B. Conservation challenge: human-carnivore conflict in CheberaChurchura National Park, Ethiopia. Greener J Biol Sci. 2013;3:108-15.

11. Dickman AJ. Complexities of conflict: the importance of considering social factors for effectively resolving human-wildlife conflict. Anim Conserv. 2010;13:458-66.

12. Fern RL. Human uniqueness as a guide to resolving conflicts between animal and human interests. Ethics Anim. 2011. https://doi.org/ 10.15368/ea.1981v2n1.2.

13. Groenewald T. A phenomenological research design illustrated. Int J Qual Methods. 2004;3(1):42-55.

14. Hilton-Taylor C, da Fonseca GAB, Aguiar JM. Edentates in the 2006 IUCN Red List. Edentata. 2006;7:54.

15. Hoare R. Lessons from 20 years of human-elephant conflict mitigation in Africa. Hum Dimens Wildl. 2015;20(4):289-95. https://doi.org/ $10.1080 / 10871209.2015 .1005855$.

16 Ižák Š. Conspiracy theory as a working method of political propaganda. Slovak J Pol Sci. 2020. https://doi.org/10.34135/sjps.200104.

17 Jaireth H. Introduction to the special issue: human-wildlife conflict and peace-building strategies. J Int Wildl Law Policy. 2008;11(2-3):99100. https://doi.org/10.1080/13880290802470125.

18 Katyal NK. Conspiracy theory. SSRN Electron J. 2002. https://doi.org/10.2139/ssrn.346500.

19. Khan MZ, Khan B, Awan MS, Begum F. Livestock depredation by large predators and its implications for conservation and livelihoods in the Karakoram Mountains of Pakistan. Oryx. 2018;52(3):519-25. https://doi.org/10.1017/s0030605316001095.

20. Lebo MJ, Weber C. An effective approach to the repeated cross-sectional design. Am J Pol Sci. 2014;59:242-58.

21 Mekonen S. Coexistence between human and wildlife: the nature, causes, and mitigations of human-wildlife conflict around Bale Mountains National Park, Southeast Ethiopia. BMC Ecol. 2020. https://doi.org/10.1186/s12898-020-00319-1.

22. Merkebu S, Yazezew D. Assessment of human-wild life conflict and the attitude of local communities to wild animal conservation around Borena Sayint National Park, Ethiopia. Int J Ecol. 2021;2021:1-8.

23. Mukeka JM, Ogutu JO, Kanga E, Røskaft E. Human-wildlife conflicts and their correlates in Narok County, Kenya. Glob Ecol Conserv. 2019. https://doi.org/10.1016/j.gecco.2019.e00620.

24 Ningyi L. Analysis of the thematic structure and thematic progression patterns of the queen's 2020 national speech. Engl Lit Lang Rev. 2020. https://doi.org/10.32861/ellr.68.147.152.

25. Reifsnider E, García AA. What's in a name? Does population health have the same meaning for all stakeholders? Public Health Nurs. 2015;32:189-90.

26. Saberwal VK, Gibbs JP, Chellam R, Johnsingh AJT. Lion-human conflict in the Gir forest, India. Conserv Biol. 1994;8(2):501-7. https://doi. org/10.1046/j.1523-1739.1994.08020501.x.

27. Salom A, Suárez ME, Destefano CA, Cereghetti J, Vargas FH, Grande JM. Human-wildlife conflicts in the Southern Yungas: what role do raptors play for local settlers? Animals. 2021;11:1428.

28. Sanderson S, Rudel TK, Horowitz B. Tropical deforestation: small farmers and land clearing in the Ecuadorian Amazon. J Wildl Manag. 1994;58:588.

29. Shanko G, Tona B, Adare B. Human-wildlife conflict around Belo-Bira Forest, Dawro Zone, Southwestern Ethiopia. Int J Ecol. 2021;2021:1-7.

30. Sharma P, Chettri N, Wangchuk K. Human-wildlife conflict in the roof of the world: understanding multidimensional perspectives through a systematic review. Ecol Evol. 2021;11:11569-86.

31. Shields L, Twycross A. The difference between quantitative and qualitative research. Paediatr Nurs. 2003;15:24-24.

32. Solomon P, O'Brien KK, Baxter L, MacLachlan D, Robinson G. Community involvement in development of evidence-informed recommendations for rehabilitation for older adults living With HIV. Prog Commun Health Partnersh Res Educ Action. 2016;10(1):83-8. https:// doi.org/10.1353/cpr.2016.0008.

33 Swami V. Social psychological origins of conspiracy theories: the case of the jewish conspiracy theory in Malaysia. Front Psychol. 2012. https://doi.org/10.3389/fpsyg.2012.00280.

34. Teshome Z. Human-wildlife conflict: challenge and management in Ethiopia: a review. Int J Emerg Trends Sci Technol. 2017;03:5004-9.

Publisher's Note Springer Nature remains neutral with regard to jurisdictional claims in published maps and institutional affiliations. 